\section{Sympathy from students}

Re: "No longer free for all."1 As a representative of Canadian medical students studying abroad, I want to thank the CMAJ for being our main source for Canadian-specific health matters. For years the CMAJ has served us for free, but we know all too well that costs of business are mounting. If fees are required for us to view $C M A J$ material less than 12 months old, we Canadians in Ireland will become less current; however, that is a small price to pay to help ensure that the journal maintains both its existence and level of quality.

Rob Obara, first-year medical student Trinity College, Dublin, Ireland

\section{REFERENCE}

1. Hébert PC. No longer free for all. CMAJ 2009;181: E244.

For the full letter, go to: www.cmaj.ca/cgi/eletters /181/11/E244\#246110

DOI:10.1503/cmaj.110-2001

\section{Tobacco lawsuits}

Re: "Destroyed documents: uncovering the science that Imperial Tobacco Canada sought to conceal."1 At the end of September, the Ontario government became the third province to file a claim against the tobacco companies to recover health care costs associated with smoking. Mere money will not bring back to life the million or so Canadians killed by tobacco, nor will it prevent hundreds of thousands of tobacco-caused deaths that will occur. Provincial litigators need to rethink their strategies. There are many healthrelated goals that could guide these lawsuits. They include a settlement that requires plain packaging of cigarettes, a reduced number of retail outlets and increased controls on the remaining ones and more support for smoking cessation programs. But these measures, important as they are, do not address the central problem: Tobacco companies continue to profit from a deadly product that will kill half its life- long users. The most important service provincial litigators could render to all Canadians would be to demand that tobacco companies be obliged to fix this problem. It is time for litigators to ask the courts to require tobacco companies to phase out tobacco.

Neil Collishaw, research director

Physicians for a Smoke-Free Canada

\section{REFERENCE}

1. Hammond D, Chaiton M, Lee A, et al. Destroyed documents: uncovering the science that Imperia Tobacco Canada sought to conceal. CMAJ 2009;181:691-8.

For the full letter, go to: www.cmaj.ca/cgi/eletters /181/10/691\#244361

DOI:10.1503/cmaj.110-2004

\section{Lack of physician scientists}

Dr. Laberge and her colleagues ${ }^{1}$ touch a very important question. One of the roots may be - at least in Sweden and Finland - a decrease in the number of medically qualified scientists. The basic sciences have difficulties attracting young medical students or recent graduates to do research and, therefore, future clinical leaders do not have hands-on experience on the creation and application of modern biomedical methods and concepts. Sweden has created special research-orientated internships for young physicians with early success, although the impact in the long term remains to be seen. It is felt that future clinicians should have a more active role in the creation of new biomedical primary discoveries so that they could more fully understand and use translational research.

Heikki Savolainen, professor

Department of Occupational Safety and Health, Tampere, Finland

\section{REFERENCE}

1. Laberge S, Albert M, Hodges BD. Perspectives of clinician and biomedical scientists on interdisciplinary health research. CMAJ 2009;181:797-803.

For the full letter, go to: www.cmaj.ca/cgi/eletters /181/11/797\#245668

DOI:10.1503/cmaj.110-2005

\section{Be careful about timelines}

Tom Koch ${ }^{1}$ precisely described the negative repercussions of suggesting to a patient that the end is near. Any discussion that places precise time frames (three to six months) is heard as a death sentence. I tell my undergraduate medical students never to use a number or time frame when discussing end of life. Discuss timing in days to weeks, weeks to months, or months to years. I always follow such estimations with a comment about the difficulty in predicting death. Even after 16 years of experience in oncology, I am occasionally off by weeks or more. Often the desire to know when the end is near is pragmatic. There may be wills to amend, the need to sell a residence, organize finances, or the desire to have family near (many of whom must come from distant locations and take time from work). Find out what these worries or concerns are, and then arrange appropriate support such as a social work consultation.

\section{Christopher Leighton MD}

University of Windsor Campus

Schulich School of Medicine \& Dentistry

Windsor, Ont.

\section{REFERENCE}

1. Koch T. End of life, year after year after year. CMAJ 2009; 181:868.

For the full letter, go to: www.cmaj.ca/cgi/eletters /181/11/868\#245436

DOI:10.1503/cmaj.110-2007

\section{A sea of salt}

I read with some bemusement the excellent review article "Effective population-wide public health interventions to promote sodium reduction." the authors are to be commended on their broad overall perspective, a cynical person might suggest that they might temper their enthusiasm by visiting any of our local supermarkets. If the goal is to truly try to limit sodium consumption to $1200-1500 \mathrm{mg}$ a day as well as having no single food item contain more than $10 \%$ of the daily total, 
they are certainly going to be hardpressed shoppers. I would submit that until industry really get serious about stopping the almost universal harmful addition of excess sodium to commercial foodstuffs (or the government actually does something), excellent articles like Dr. Mohan's will amount to little more than wishful thinking.

\section{Malcolm Brigden MD}

Medical oncologist

Sault Ste. Marie, Ont.

\section{REFERENCE}

1. Mohan S, Campbell NRC, Willis K. Effective population-wide public health interventions to promote sodium reduction. CMAJ 2009;181:605-09.

For the full letter, go to: www.cmaj.ca/cgi/eletters /181/9/605\#235107

DOI:10.1503/cmaj.110-2006

\section{Diagnosis of asthma}

A significant weakness of the excellent work by Kaplan and colleagues ${ }^{1}$ relates to a lack of discussion on the spirometric overlap between asthma and chronic obstructive pulmonary disease (COPD) and how this may lead to disease misclassification. This clarification is important since their diagnostic algorithm for asthma, Figure 1, contains a decision node labelled "Spirometry results consistent with asthma" referring to improvements in forced expiratory volume in one second (FEV1) after bronchodilator challenge; changes that can also be seen in many patients with $\mathrm{COPD}^{2}$. It is also important to provide clarification about what is meant by "reversibility of airflow obstruction" as this applies to asthma and COPD.

It could be argued that airflow obstruction defined by a reduction in the ratio of FEV1 and forced vital capacity (FVC) is irreversible in COPD since, by definition, it must remain below some predetermined value after bronchodilator challenge. However, a persistent reduction in FEV1/FVC after bronchodilation in COPD may be associated with significant changes in airway calibre (FEV1) similar to that recommended for the spirometric diagnosis of asthma. Furthermore, the FEV1/FVC may remain reduced after bronchodilator challenge in asthma; highlighting the spirometric overlap that may exist between asthma and COPD in terms of FEV1 and FEV1/FVC changes after bronchodilator challenge. Therefore, COPD can be characterized by a persistent reduction in FEV1/FVC after bronchodilation irrespective of airway calibre changes.

For spirometric diagnoses of asthma, criteria for changes in airway calibre must be met irrespective of the FEV1/ FVC value; the latter is often normal in asthmatics. This information is not clearly apparent in the diagnostic algorithm for asthma, Figure 1, and could result in disease misclassification in some patients.

\section{Anthony D. D'Urzo MD MSc \\ Chair, Primary Care Respiratory Alliance of Canada \\ Department of Family and Community \\ Medicine, Toronto, Ont.}

\section{REFERENCES}

1. Kaplan AG, Balter MS, Bell AD et al. Diagnosis of Asthma in Adults. CMAJ 2009;181:E210-20.

2. Tashkin DP, Celli B, Senn S, et al. A 4-year trial of Tiotropium in Chronic Obstructive Pulmonary Disease. N Engl J Med 2008;359:1543-54.

For the full letter, go to: www.cmaj.ca/cgi/eletters /181/10/E210\#243521

DOI:10.1503/cmaj.110-2010

\section{Social pain and opioid use}

The letter by Susan Rosenthal ${ }^{1}$ indicates, likely by intention, a simplification tying opioid use to social pain. To me, increasing opioid use has more to do with physicians finally learning that unmitigated pain, especially chronic pain, is no longer acceptable. My own reality is that chronic use with judicious controls (e.g., better acceptance recently for giving methadone for chronic pain) can often allow some reasonable function. As GPs, we are often truly the first to triage for chronic pain patients, but also the option of last resort required to keep prescribing with frustrating "triplicate/duplicate" security-laden prescription pads, periodic urine screening and so on. Being asked to take on police-type thinking on top of all this can be a challenge, very dif- ferent from the therapeutic impulse that underlies our work ethic.

\section{John de Couto MD}

Burnaby, BC

\section{REFERENCE}

1. Rosenthal SM. Social pain and opioid use [letter] CMAJ 2009; 181:827-a

For the full letter, go to: www.cmaj.ca/cgi/eletters /181/11/827-a\#249094

DOI:10.1503/cmaj.110-2000

\section{CIHR and Prigent}

The debate over the appointment of a seasoned scientist with private-sector experience to the governing council of the Canadian Institutes of Health Research $^{1}$ (CIHR) is based on innuendo rather than fact. CIHR should be commended for appointing Dr. Bernard Prigent. He brings strong international credentials in pharmaceutical research and development and has been recognized by his peers in the scientific and academic community for championing principled partnerships between industry, academia and governments aimed at improving Canada's performance in health research. Furthermore, the governing council does not make decisions with respect to which researchers/projects will be funded, as this is the responsibility of the scientific council, based on the advice of peer review panels. Dr. Prigent's appointment is consistent with CIHR's mission, which is "the creation of new knowledge and its translation into improved health for Canadians, more effective health services and products and a strengthened Canadian health care system."

Russell Williams, president Canada's Research-Based Pharmaceutical Companies (Rx\&D)

Yves Morin, cardiologist and chair Rx\&D Health Research Foundation Ottawa, Ont.

\section{REFERENCE}

1. Silversides A. CIHR appointment stirs controversy. CMAJ 2009;181:E256-57.

For the full letter, go to: www.cmaj.ca/cgi/eletters /181/11/E256\#247532

DOI:10.1503/cmaj.110-2003 